\title{
6th EPS General Condensed Matter Physics Conference 1986
}

This year the CMD General Conference moved to the north of Europe, specifically to the Royal Institute of Technology in Stockholm. At a time of the year - 22-25 March — when spring had come to most of the continent, the participants were reminded of the location by occasionally having to wade through snow to reach the lectures. However the weather provided the only significant practical hitch in the entire conference. Otherwise the dedicated efforts of the local organizers ensured that everything operated smoothly and effectively, including the enjoyable social programme with a reception at the Stockholm town hall and a typical Swedish dinner at Skansen.

The main purposes of the CMD conferences are to bring together the condensed matter physicists of Europe for fruitful scientific interchanges, and to present the latest advances in the subject to non-specialist audiences. The attendance seems to have settled down at about 4-500 itinerant physicists plus the local solid-state community. In contrast to Berlin last year, where the local community is much larger, the total attendance this year was down to 5-600, but some 28 different countries were in evidence. This number makes for a lively interaction between the participants and the main conference building, appropriately dubbed "sing-sing", turned out to be well suited to the purpose. It would probably be useful to increase the attendance at CMD conferences somewhat, but they do function successfully at the present level, and it is very questionable whether we should aspire to the gargantuan proportions of the APS March meeting, where finding anyone among the 3500 participants can be a formidable task.

The Programme Committee, of which I was Chairman, faced the daunting challenge of selecting 90 plenary, invited and contributed papers from the several hundred suggestions received through various channels. This was largely accomplished in a hectic but extremely constructive 24 hours in Copenhagen last June, when the Committee also had the opportunity of visiting Niels Bohr's Institute in his centenary year. Thanks to their excellent work and the acceptance rate of over
$90 \%$ by the invited speakers, only minor adjustments had to be made to the programme after that.

The plenary sessions were of exceptional interest, comprising lectures on electronic structure by Ole Krogh Andersen, ocean waves by Bjørn Gjevik, the glass transition by Sam Edwards and a masterful survey of open problems in condensed matter physics by Leo Falicov. In addition Ferenc Mezei gave the Hewlett-Packard Prize Lecture on neutron spin-echo spectroscopy, and Ivar Giaever's amusing and informative account of his experiences as a physicist in biology was an enjoyable prelude to the reception. The symposia reflected the wide spectrum of interests of condensed matter physicists, incorporating quantum mechanical and classical phenomena, high and low temperatures, liquids and solids, metals, semiconductors and insulators, and pure and applied research in physics, chemistry and biology. In chronological order the topics were: Photoemission from magnetic materials, Fractals, Defects, f-electrons - localized and itinerant, Microstructural physics, Fast spectroscopy, Low temperature phenomena, Chaos, Interactions of lasers with matter, Surface dynamics and reactions, Condensed matter and biology, Optical bistability, Random fields and phase transitions, Applications of solid-state phenomena, Electrons in metals, Heterogeneous quantum systems, Ordered soft matter, Frontiers in condensed matter physics, The two-dimensional electron gas, Quasicrystals, and Polymers and chains. Most of the plenary and symposium papers will be published in a forthcoming volume of Physica Scripta. Some 350 posters described work which will no doubt form the basis for the symposia in the next CMD conference in Pisa.

The Programme Committee had set itself the goal of becoming equally unpopular with all the CMD Section Chairmen when deciding the scientific balance of the programme, and their ambition in this respect was generally satisfied. However the geographical balance was strongly skewed towards northwestern Europe. This was partly because the centre of gravity of condensed matter physics in Europe lies in this area, but there was also an element of

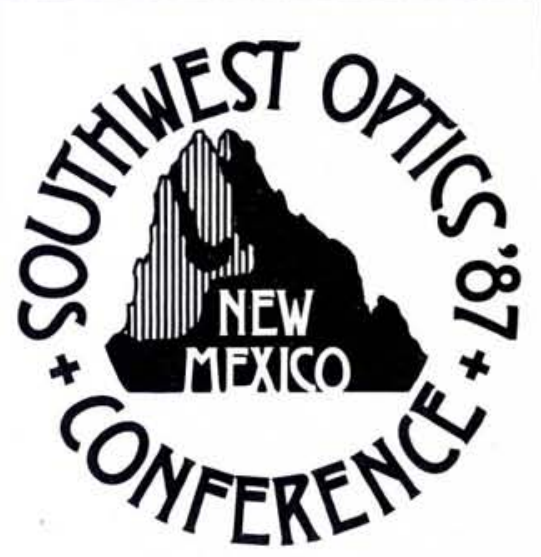

Albuquerque Convention Center - Albuquerque, NM February 9-13, 1987

\section{Topical Meetings on:}

SEMICONDUCTOR LASERS • Semiconductor diode lasers remain the subject of intensive worldwide development efforts with rapid progress being made in many areas of device design and performance. In addition to their use in optical fiber systems, other applications have been identified and lasers are being fabricated to meet many different system requirements. This meeting will treat all aspects of laser design, development and characterization.

OPTICS IN ADVERSE ENVIRONMENTS - Optical materials are being applied in ever more stressing environmental conditions. The purpose of this meeting is to bring together researchers with experience in all aspects (materials, design, fabrication, testing and performance) of optics in highly adverse environments for an exchange of results, techniques and discussion of future research directions.

LASERS IN MATERIAL DIAGNOSTICS - Laser and optical techniques are increasingly important for diagnos. tics of a wide variety of materials and processing technologies. These techniques are being used both for analytic measurements and as tools to probe new materials and effects. This meeting will bring together workers from all of these areas for the exchange of results and of new directions for research.

\section{ABSTRACT DEADLINE:}

October 20, 1986

Cosponsored by Lasers \& Electro-Optics Society of IEEE and Optical Society of America.

For technical information contact: Optical Society of America Meetings Department

1816 Jefferson PI., N.W.

Washington, DC 20036 (202) 223.0920

For exhibit information contact: Larry Lotridge, Exhibits Manager Optical Society of America

1816 Jefferson PI., N.W.

Washington, DC 20036

(202) 223-0920 
unintended bias in the selection of speakers, exacerbated by the fact that the representatives on the Programme Committee from the East and South were, for various reasons, unable to participate very actively in its work. In order to achieve the desired balance in the future, I believe that it is vital that the scientific communities from these regions play a more active role in its preparation, particularly by sending in more suggestions for invited speakers.

Much of the success of the Stockholm Conference was due to Hermann Grimmeiss, the Conference Chairman, and Göran Grimvall, the Chairman of the Local Organizing Committee, who were willing to take infinite pains to ensure that everything functioned smoothly. I am grateful both to them and to the Programme Committee for an unusually pleasant and constructive collaboration. The CMD General Conference is now firmly established as an annual event whose future success seems assured. At the time of his retirement as Chairman of the CMD Board, it is appropriate to recall that the series was started through the initiative and enthusiasm of Jozef Devreese.

\section{A.R. Mackintosh}

\section{EPS Workshop}

Organised primarily for the Associate Members of the European Physical Society a Workshop on Low Resolution Pyroelectric Arrays: Material, Signal Analysis, Integration and Application, as announced by ACAPPI to Council at its meeting in March (Europhys. News, 17 (1986)5, 58) will be held in Bad Honnef, FRG from 26 to 29 April 1987.

This is the first of what is intended to be a running series devoted to fields of physics which are emerging from the laboratory into applications, or where particular problem areas of common interest to a number of our Associate Members have been identified. Although the meetings are not rigorously restricted to Associate Members, they will have priority when places are reserved. Attendance is limited to about 40 people.

The aim of the Bad Honnef workshop is to bring together people interested in the research and development of pyroelectric and infrared detector arrays and their industrial applications for an exchange of information and to gain an overview of the field and its newest developments. The major presentations will be given by invited specialists, but contributed presentations will also be welcome.

Further information on the scientific programme can be obtained from $\mathrm{H}$. Melchior, ETH, Zurich and on the practical organisation from the EPS Secretariat.

\section{Associate Members}

Newest Associate Member of EPS is: DFVLR-Deutsche Forschungs- und Versuchsanstalt für Luft- und Raumfahrt e.V. Linder Höhe, D-Köln-Porz

We apologise for omitting from the list of Associate Members published in June: IMEC-Interuniversitair Micro-ElektronicaCentrum VZW Kapeldreef 75 B-3030 Leuven

\section{Recent Elections}

Since publishing the June Directory the following changes have been notified to the Secretariat:

\section{Astronomy and Astrophysics Division:}

Following the elections within the Board Ch. M.C.E. Huber

Institut für Astronomie

ETH Zentrum

$\mathrm{CH}-8092$ Zürich

T. (1) $2563813 / 3632$ Tx. 531178 eth bi

Sec. G. Bignami

Istituto Fisica Cosmica

CNR

15/A via Bassini, I-20133 Milano

T. (2) $299653 \quad$ Tx. 313839 muacnr

\section{Plasma Physics Division}

$K$. Appert of the CRPP, Lausanne combines the position of Vice-Chairman and Treasurer. D. Sweetman of the Culham Laboratory remains a member of the Board.

\section{New Members of the European Physical Society}

\section{CATEGORY 4a)}

J. Nührenberg, Garching, D

Ch. Serre, Geneva, $\mathrm{CH}$

Y.K. Sharma, Garching, D

\section{CATEGORY 4c)}

Belgian Physical Society

R. Gastmans, Leuven

P. Marage, Brussels

E.J. Petit, Namur

C. Pierre, Brussels

C. Waelkens, Heverlee

Danish Physical Society

A. Winter, Copenhagen

Eötvös Lorand Physical Society

M. Fried, Budapest

V. Németh, Budapest

French Physical Society

M. Aboites, Mexico City, Mexico

I. Adram, St. Cloud

J. Baudon, Paris

Ch. Bonnelle, Paris

Ph. Brossier, Gif-sur-Yvette

F. Cyrot, Grenoble

J.M. Dilhac, Toulouse

F. Nallet, Bordeaux

E. Pauli, Paris

F. Tasset, Grenoble

J. Teillet, Mt. St. Aignan

C. Wolff, Mulhouse
German Physical Society

F. Blum, Aachen

Ch. Heiden, Giessen

S. Hunklinger, Heidelberg

K. Mavrommatis, Aachen

Hellenic Physical Society

A.C. Cefalas, Athens

M. Kompitsas, Athens

The Institute of Physics

R.J. Cashmore, Oxford

R. Garcia-Molina, Alacant, E

M. Lakshmanan, Tiruchirapalli, India

D.J. Pritchard, Southampton

J.C. Schoutten, Oxford

Israel Physical Society

G. Alexander, Tel-Aviv

Italian Physical Society

F. Casagrande, Milan

M. Milani, Milan

E. Sindoni, Milan

The Netherlands' Physical Society

T.J.H. Donné, Nieuwegein

W. van Neerven, Leiden

J.M. van Ruitenbeek,

Saint Egrève, $F$

W.T. Wenckebach, Leiden

E. Westerhof, Utrecht
Norwegian Physical Society

O. Kjeldseth-Moe, Oslo

R.W. Time, Stavanger

Physical Section, Union of

Czechoslovak Mathematicians and Physicists

J. Pantoflicek, Prague

Polish Physical Society

F. Bylicki, Torun

W. Debski, Warsaw

T. Goworek, Lublin

J. Karwowski, Torun

S. Legowski, Torun

K.W. Lesniak, Warsaw

K. Meres, Krakow

J. Okolowicz, Krakow

R.S. Romaniuk, Warsaw

J. Szudy, Torun

Portuguese Physical Society

A. Correia-Diogo, Lisbon

M. de J. De Matos Gomes, Braga

J.M. Monteiro Moreira, Porto

V.J. Rocha Vieira, Lisbon

M. Telo Da Gama, Lisbon

A. Vallera, Lisbon

Romanian National Committee for Physics

M. Apostol, Bucharest

I. Baldea, Bucharest
Spanish Royal Society of

Physics

J.S. Dehesa, Granada

A. Ruiz, Santander

Swiss Physical Society

D. Issler, Bern

J.-B. Jeanneret, Geneva

\section{CATEGORY 4d)}

American Physical Society B. Bederson, New York, NY A.P. de Ruiter, Amsterdam, NL

F.B. Marcus, Lausanne, $\mathrm{CH}$

French Optical Society

B. Fillol, Paris

J.P. Gauthier, Pomponne

R. Genisson, Paris

D. Gerbet, Arcueil

J.-P. Herriau, Orsay

M. May, Paris

J. Moirez, Paris

J. Morhange, Marseille

M. Papuchon, Orsay

F. Samuel, Les Ulis

R. Stehlé, Bois Colombes

\section{Australian Institute of Physics}

M.M. Kaila, Lae, Papua, New Guinea 